\title{
Comparison of $\mathrm{Ca}^{2+}$ mobilizing activities of cyclic ADP-ribose and inositol trisphosphate
}

Peter J. Dargie, Mark C. Agre, and Hon Cheung Lee

Department of Physiology

6-245 Millard Hall

University of Minnesota

Minneapolis, MN 55455

We have previously shown that a metabolite of $\mathrm{NAD}^{+}$generated by an enzyme present in sea urchin eggs and mammalian tissues can mobilize intracellular $\mathrm{Ca}^{2+}$ in the eggs. Structural determination established it to be a cyclized ADP-ribose, and the name cyclic ADP-ribose (CADPR) has been proposed. In this study, $\mathrm{Ca}^{2+}$ mobilizations induced by CADPR and inositol trisphosphate $\left(\mathrm{IP}_{3}\right)$ in sea urchin egg homogenates were monitored with $\mathrm{Ca}^{2+}$ indicators and $\mathrm{Ca}^{2+}$-specific electrodes. Both methods showed that CADPR can release $\mathrm{Ca}^{2+}$ from egg homogenates. Evidence indicated that it did not act as a nonspecific $\mathrm{Ca}^{2+}$-ionophore or as a blocker of the microsomal $\mathrm{Ca}^{2+}$-transport; instead, it was likely to be operating through a specific receptor system. This was supported by its half-maximal effective concentration of $18 \mathrm{nM}$, which was 7 times lower than that of $I P_{3}$. The receptor for CADPR appeared to be different from that of $I P_{3}$ because heparin, an inhibitor of $I P_{3}$ binding, had no effect on the CADPR action. The $\mathrm{Ca}^{2+}$ releases induced by CADPR and $I P_{3}$ were not additive and had an inverse relationship, indicating overlapping stores were mobilized. Microinjection of CADPR into intact eggs induced transient intracellular $\mathrm{Ca}^{2+}$ changes and activated the cortical reaction. The in vivo effectiveness of CADPR was directly comparable with $\mathrm{IP}_{3}$ and neither required external $\mathrm{Ca}^{2+}$. In addition, both were effective in activating the eggs to undergo multiple nuclear cycles and DNA synthesis. These results suggest that CADPR could function as a second messenger in sea urchin eggs.

\section{Introduction}

In a number of cell systems, inositol trisphosphate $\left(\mathrm{IP}_{3}\right)$ has been shown to be a second

\footnotetext{
Abbreviations: cADPR, cyclic ADP-ribose; EGTA, [ethylene-bis(oxyethylenenitrilo)]tetraacetic acid; $\mathrm{IP}_{3}$, inositol 1,4,5-trisphosphate.
}

messenger for transducing surface-receptor activation into mobilization of internal $\mathrm{Ca}^{2+}$ stores (Berridge and Irvine, 1989). The enzymatic pathway that generates $I P_{3}$ is also known to be responsible for producing other messenger molecules. The most prominent one is diacylglycerol, an activator of protein kinase C. Stimulation of protein kinase $C$ by diacylglycerol results in phosphorylation of a variety of proteins and produces profound effects on various cellular activities (Nishizuka, 1984). In addition, at least two of the multitude of metabolites of $\mathrm{IP}_{3}$, namely, $\mathrm{IP}_{4}$ and cyclic-IP $\mathrm{P}_{3}$, have been suggested to have second-messenger functions of their own (Wilson et al., 1985; Changya et al., 1989). Activation of the $\mathrm{IP}_{3}$ pathway, therefore, results in not only mobilization of internal $\mathrm{Ca}^{2+}$ but also turning on a family of cellular processes through protein phosphorylations by protein kinase $\mathrm{C}$ and through generation of other $\mathrm{IP}_{3}$-related messengers. It thus appears that the $\mathrm{IP}_{3}$ pathway is, perhaps, acting more like a master switch for general activation of a cell than as a specific mean for $\mathrm{Ca}^{2+}$ mobilization. This raises the question of whether messenger molecules more specific for $\mathrm{Ca}^{2+}$ mobilization than $\mathrm{IP}_{3}$ could exist.

The sea urchin egg appears to be a good cellular system for addressing this question because multiple intracellular $\mathrm{Ca}^{2+}$ transients occur during its fertilization and early development (Poenie et al., 1985). The first of these transients occurs at fertilization and is triggered by surface interactions between the fertilizing sperm and the egg. Similar to other cellular systems, $\mathbb{I P}_{3}$ has been shown to be involved in transducing the signal from the sperm receptor on the surface of the egg to mobilization of intracellular $\mathrm{Ca}^{2+}$ stores (Kamel et al., 1985; Swann and Whitaker, 1986). The source of $\mathrm{Ca}^{2+}$ for the later transients is also internal because it is known that the early development of the zygote, similar to fertilization, does not require external $\mathrm{Ca}^{2+}$ (Schmidt et al., 1982). However, in contrast to the fertilization transient, the subsequent $\mathrm{Ca}^{2+}$ transients occur in the absence of surface-receptor activation and correlate, instead, with cellular events that are developmentally pro- 
gramed and are likely to be regulated by an internal timing mechanism, such as pronucleus migration, nuclear membrane breakdown, and mitosis (Poenie et al., 1985). Therefore, the signaling mechanism for these later transients could be basically different from the surfacereceptor-activated transient that occurs at fertilization.

Using microsomes prepared from sea urchin eggs as a biological assay for $\mathrm{Ca}^{2+}$ activators, we have identified a metabolite of $\mathrm{NAD}^{+}$that has $\mathrm{Ca}^{2+}$ mobilizing activity (Clapper and Lee, 1985; Clapper et al., 1987). Structural determination of the metabolite indicated it is a cyclized ADP-ribose, and the name cyclic ADPribose (cADPR) has been proposed (Lee et al., 1989). The enzyme responsible for producing CADPR was found to be present not only in sea urchin eggs but also in a wide variety of mammalian tissue extracts, suggesting the generality of the system (Rusinko and Lee, 1989). In this study we undertake a detailed comparison of $\mathrm{Ca}^{2+}$ mobilizing activities of $\mathrm{CADPR}$ and $\mathrm{IP}_{3}$ in sea urchin eggs. Results show that CADPR is as potent as $\mathrm{IP}_{3}$ in mobilizing $\mathrm{Ca}^{2+}$ in both microsomes and intact eggs. Evidence is presented indicating that both activators release $\mathrm{Ca}^{2+}$ from the same compartment, and yet the receptors for them appear to be different.

\section{Results}

\section{Mobilization of $\mathrm{Ca}^{2+}$ in egg homogenates measured by fluo 3}

Sea urchin egg homogenates were prepared as described in the Methods section and incubated at $17^{\circ} \mathrm{C}$ for $2-3 \mathrm{~h}$ with ATP for loading of the $\mathrm{Ca}^{2+}$ stores. Release of $\mathrm{Ca}^{2+}$ from these stores was monitored using various fluorescent $\mathrm{Ca}^{2+}$ indicators (quin 2, fura 2, indo 1, and fluo 3) with similar results. For most of the experiments presented in this study, fluo 3 was chosen because its dissociation constant was closer to the steady state levels of the ambient $\mathrm{Ca}^{2+}$ concentration of the homogenates and thus provided the most sensitive response to $\mathrm{Ca}^{2+}$ changes. As shown in Figure 1, addition of CADPR to egg homogenates elicited a rapid change in fluo 3 fluorescence, indicating $\mathrm{Ca}^{2+}$ release from the microsomes (trace a). This was followed by a slower reuptake of the released $\mathrm{Ca}^{2+}$. The homogenate then became desensitized to CADPR because no release was seen with a further addition of CADPR, although most of the $\mathrm{Ca}^{2+}$ had been resequestered. The desensitization was specific for cADPR because addition of an unrelated $\mathrm{Ca}^{2+}$ activator such as
$\mathrm{IP}_{3}$ (Figure 1a) or ionomycin (data not shown) could still trigger $\mathrm{Ca}^{2+}$ release. The desensitization appeared to be a general characteristic of the egg microsomes because we have previously observed that large doses of $\mathrm{IP}_{3}$ can also induce similar desensitization specific to itself (Clapper and Lee, 1985; Clapper et al., 1987). The requirement of specific functioning of the microsomes ruled out the possibility that the cADPR induced response was due to some artifactual interactions between CADPR and fluo 3.

If CADPR indeed induced $\mathrm{Ca}^{2+}$ release from the microsomes, it should be possible to eliminate the response by increasing the $\mathrm{Ca}^{2+}$-buffering power of the homogenate. This was done by adding [ethylene-bis(oxyethylenenitrilo)]tetraacetic acid (EGTA) to the homogenate followed by enough $\mathrm{Ca}^{2+}$ to bring the fluorescence back to the original level (trace $b$ in Figure 1). This procedure increased the $\mathrm{Ca}^{2+}$-buffering power of the homogenate without altering its steady state $\mathrm{Ca}^{2+}$ concentration and greatly diminished the cADPR-induced response. Further increase in $\mathrm{Ca}^{2+}$ buffering power practically eliminated the response (trace $c$ of Figure 1).

The $\mathrm{Ca}^{2+}$-releasing activity of cADPR is heat labile. Addition of heated CADPR (10 min in boiling water) at the same dosage as in trace a did not elicit any $\mathrm{Ca}^{2+}$ release, and only partial release was seen with a second addition (trace $d$ of Figure 1). Complete destruction of its activity was seen with a 20-min heating in boiling water. As shown in trace e of Figure 1, addition of even five times the dosage of the unheated control did not produce any release. It is therefore obvious that the CADPR-induced response could not be due to contaminating $\mathrm{Ca}^{2+}$ in the sample. This set of control experiments provides strong evidence that the fluorimetric assay was indeed monitoring specific $\mathrm{Ca}^{2+}$ release from the microsomes. As further support, we repeated the same set of control experiments using a $\mathrm{Ca}^{2+}$ electrode to monitor the $\mathrm{Ca}^{2+}$ release and obtained similar results.

\section{Mechanism of cADPR-induced $\mathrm{Ca}^{2+}$ release}

Possible mechanisms of how CADPR induces $\mathrm{Ca}^{2+}$ release were investigated. Figure 2 shows results indicating cADPR did not release $\mathrm{Ca}^{2+}$ through blocking of the microsomal $\mathrm{Ca}^{2+}$-transporting mechanism. We have previously shown that the microsomal $\mathrm{Ca}^{2+}$ transport required ATP and could be blocked by its removal (Clapper and Lee, 1985). Addition of an exogenous ATPase; Apyrase, to hydrolyze all the ATP in 


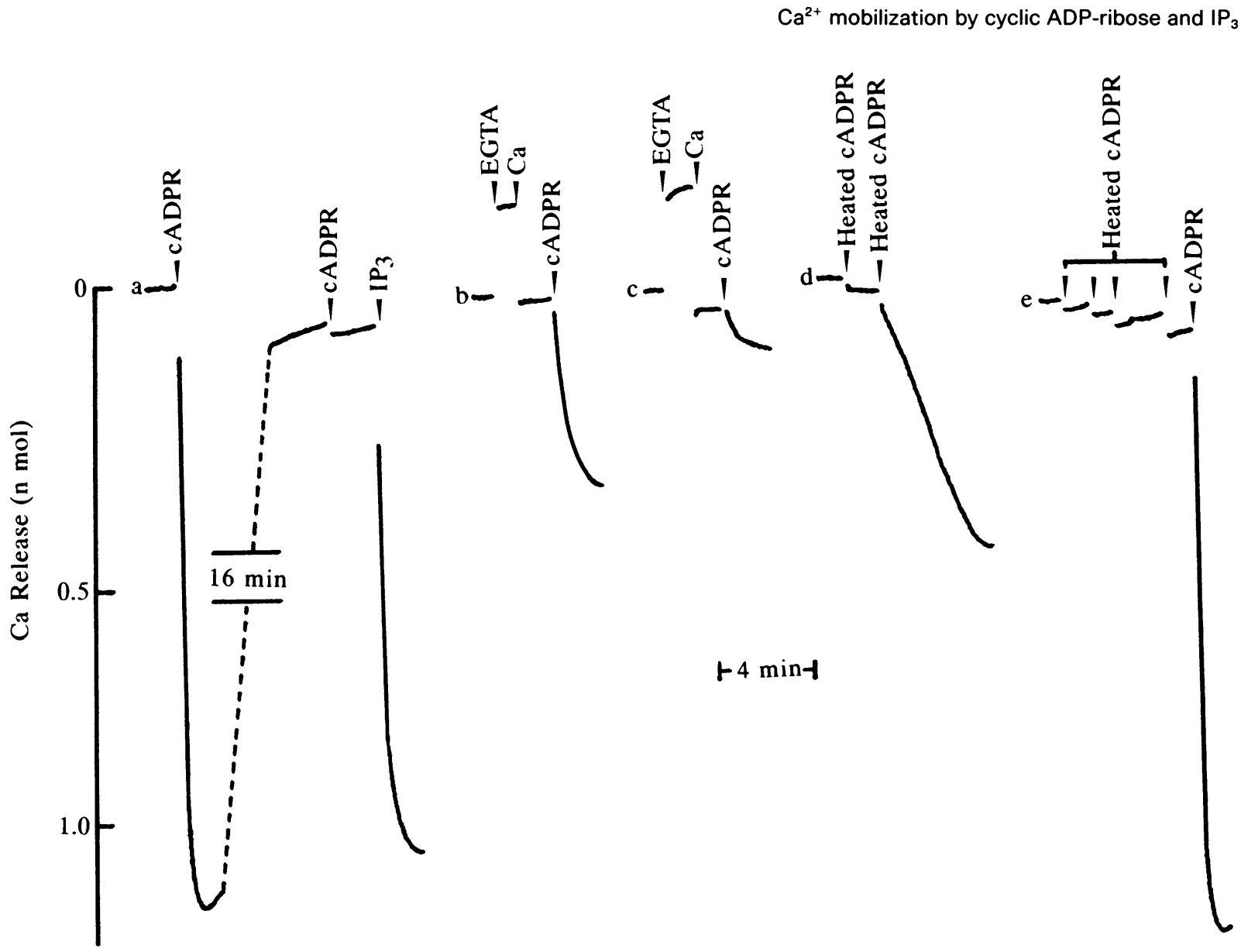

Figure 1. Measurements of $\mathrm{Ca}^{2+}$ release in egg homogenates. Release of $\mathrm{Ca}^{2+}$ in egg homogenates was monitored fluorimetrically using the indicator fluo 3. A $0.2-\mathrm{ml}$ aliquot of $2.5 \%$ egg homogenate was used for each of the experiments shown. Additions were as follows: (a) first addition of CADPR, $0.29 \mu \mathrm{M}$; second addition of CADPR, $0.57 \mu \mathrm{M}$; IP, $1 \mu \mathrm{M}$. (b) EGTA, 25 $\mu \mathrm{M}$; Ca, $6.25 \mu \mathrm{M}$; CADPR, $0.29 \mu \mathrm{M}$. (c) EGTA, $0.1 \mathrm{mM}$; Ca, $25 \mu \mathrm{M}$; CADPR, $0.29 \mu \mathrm{M}$. (d) CADPR was heat inactivated in boiling water for $10 \mathrm{~min}$ (heated CADPR), and each addition was $0.29 \mu \mathrm{M}$. (e) cADPR was heat inactivated in boiling water for 20 min (Heated cADPR). The first three additions of heated CADPR were $0.29 \mu \mathrm{M}$ each, and the last one was $0.57 \mu \mathrm{M}$. CADPR was added to a final concentration of $0.29 \mu \mathrm{M}$.

the homogenate produced only a slow release of $\mathrm{Ca}^{2+}$ after an initial lag period of $\sim 60 \mathrm{~s}$ (trace a in Figure 2). In contrast, cADPR always elicited a rapid $\mathrm{Ca}^{2+}$ release whether it was added before (traces $d$ and $e$ in Figure 2) or at various times after (traces b and $c$ in Figure 2) the addition of Apyrase. Doubling the Apyrase concentration did not increase the rate of $\mathrm{Ca}^{2+}$ leakage as shown in trace $c$ of Figure 2, indicating that ATP removal by Apyrase was not a rate-limiting factor. Comparing traces a and $c$ of Figure 2, however, it can be seen that the lag periods before the beginning of $\mathrm{Ca}^{2+}$ leakage from the microsomes was shortened at the higher Apyrase concentration. Normally, the cADPR-induced release was followed by $\mathrm{Ca}^{2+}$ reuptake (traces $d$ and e). In the presence of Apyrase, although cADPR-induced release occurred as usual, the reuptake process was completely blocked (traces $b$ and $c$ ). Furthermore, addition of Apyrase during the reuptake process blocked its progress after a lag of about 60 seconds and then was followed by $\mathrm{Ca}^{2+}$ leakage as shown in trace e of Figure 2.

The cyclic structure of CADPR, with its two negatively charged phosphate groups (Lee et al., 1989), resembles the structure of an ionophore. However, the fact that it can induce desensitization in the microsomes (trace a in Figure 1) argues against its functioning as an ionophore permeabilizing membranes nonspecifically. Indeed, addition of CADPR to desensitized microsomes did not release more $\mathrm{Ca}^{2+}$, even when the microsomal $\mathrm{Ca}^{2+}$-transport system was blocked by ATP removal with Apyrase (trace e of Figure 2).

The desensitization, however, did suggest that CADPR may be operating through a specific 


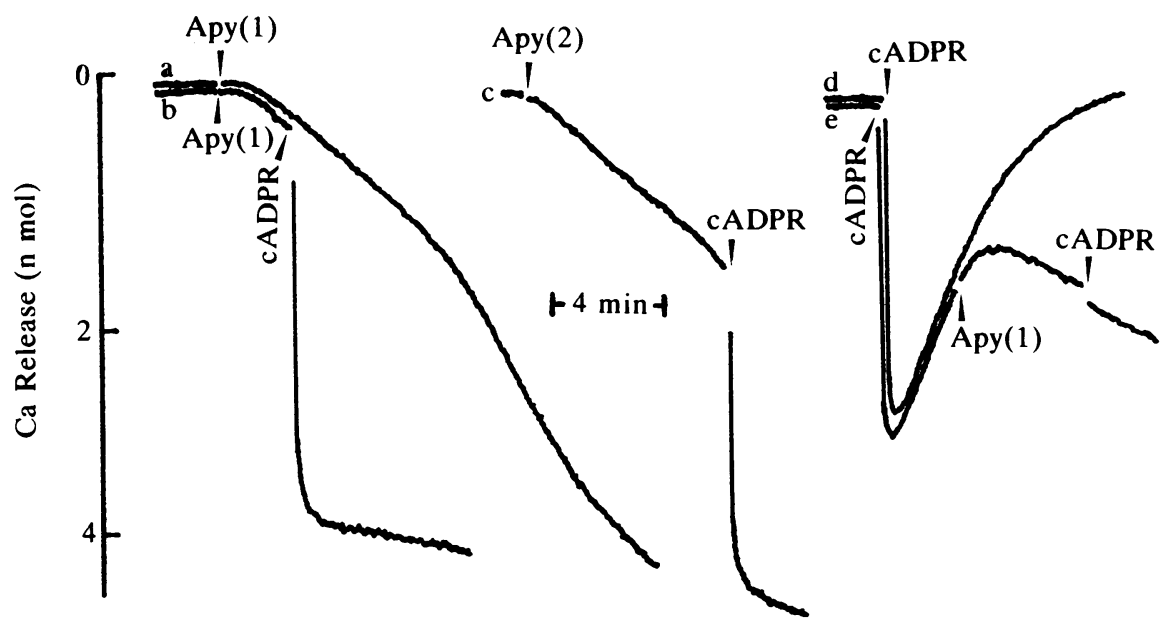

Figure 2. Effects of removal of ATP on $\mathrm{Ca}^{2+}$ release. Egg homogenates were prepared as described in the Methods section except that the enzymatic system for regenerating ATP was not included. The final ATP concentration in the homogenates was $0.5 \mathrm{mM}$. A $0.8-\mathrm{ml}$ aliquot of $2.5 \% \mathrm{egg}$ homogenate was used in each experiment shown. ATP removal was effected by the addition of Apyrase (Apy), a general ATPase, to hydrolyze the ATP in the homogenates. Additions were as follows: (a) Apy(1), 1 unit/ml of Apyrase. One unit of Apyrase will hydrolyze $1 \mu \mathrm{mol}$ of ATP per min at $\mathrm{pH} 6.5$ at $30^{\circ} \mathrm{C}$. (b) Apy(1), 1 unit $/ \mathrm{ml}$ of Apyrase; cADPR 71 nM. (c) Apy(2), 2 units/ml of Apyrase; cADPR, $71 \mathrm{nM}$. (d) cADPR, 71 nM. (e) Each addition of cADPR was $71 \mathrm{nM}$; Apy(1), 1 unit/ml Apyrase.

receptor system. This is supported by the very low half-maximal effective concentration of cADPR. Figure 3 compares directly the doseresponse curves of $C A D P R$ and $I P_{3}$, which were constructed using the same egg homogenate preparation. The half-maximal concentration of CADPR was $\sim 18 \mathrm{nM}$, which was 7 times lower than the $130 \mathrm{nM}$ of that of IP . From four other homogenate preparations, the half-maximal concentration of CADPR was found to be between 10 and $50 \mathrm{nM}$ and was always less than that of $\mathrm{IP}_{3}$ when measured in the same preparation. The maximal $\mathrm{Ca}^{2+}$ released by the two activators was about the same and was $\sim 30 \%$ of the total ionomycin-releasable $\mathrm{Ca}^{2+}$.

It has been established that $\mathrm{IP}_{3}$ is operating through a specific receptor protein of $260 \mathrm{kDa}$ (Supattapone et al., 1988) and that heparin is a competitive inhibitor of $\mathrm{IP}_{3}$ binding to this receptor (Worley et al., 1987). It is therefore of interest to see if heparin can block the action of cADPR. Traces $a$ and $b$ in Figure 4 show the $\mathrm{Ca}^{2+}$ release induced by a maximum dose of cADPR and $\mathrm{IP}_{3}$ respectively. The amount released was again similar. Addition of $50 \mu \mathrm{g} / \mathrm{ml}$ heparin to the homogenate resulted in partial block of the $\mathrm{IP}_{3}$-induced $\mathrm{Ca}^{2+}$ release (trace $\mathrm{c}$ ). Increasing heparin concentration increased the inhibition (trace d), and, at $187 \mu \mathrm{g} / \mathrm{ml}$ of heparin, the $\mathrm{IP}_{3}$-induced release was completely blocked (trace e). No inhibition was seen, however, on the cADPR-induced release (trace e). Both the rate and the amount of $\mathrm{Ca}^{2+}$ release were very similar to the control (trace a). This result indicates that the $\mathrm{Ca}^{2+}$-release system activated by CADPR is likely to be different from that of $\mathrm{IP}_{3}$.

Also shown in Figure 4 is the inverse pattern of $\mathrm{Ca}^{2+}$ release induced by $\mathrm{IP}_{3}$ and CADPR as the heparin concentration was increased. At 50 $\mu \mathrm{g} / \mathrm{ml}$ heparin, $\mathrm{IP}_{3}$ released $\sim 2 \mathrm{nmol}$ of $\mathrm{Ca}^{2+}$, and subsequent addition of CADPR released about the same amount (trace c). At $100 \mu \mathrm{g} / \mathrm{ml}$ of heparin, $\mathrm{IP}_{3}$ release was reduced to $\sim 1 \mathrm{nmol}$,

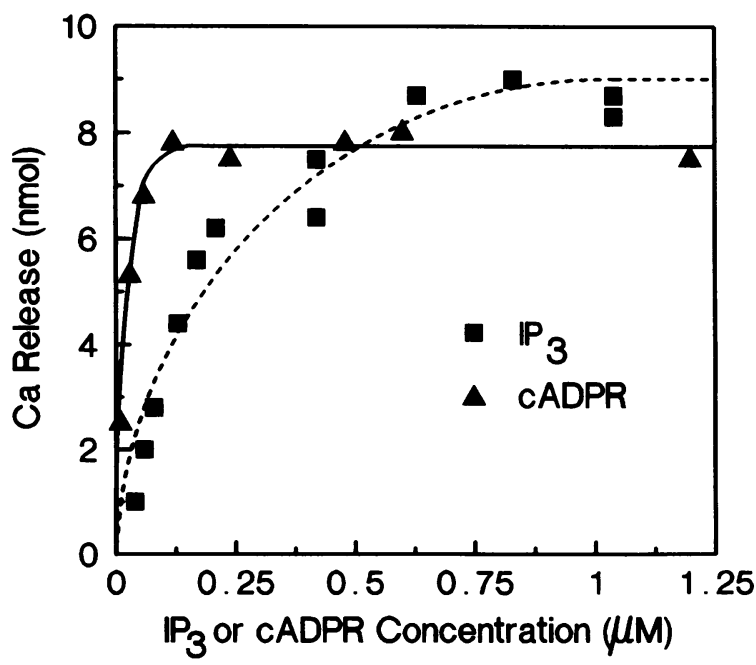

Figure 3. Comparison of the dose-response curves for CADPR and $\mathrm{IP}_{3} . \mathrm{Ca}^{2+}$ release from $2.5 \%$ egg homogenates $(0.8 \mathrm{ml})$ was measured fluorimetrically using indo 1 instead of fluo 3. 
$\mathrm{Ca}^{2+}$ mobilization by cyclic ADP-ribose and $\mathrm{IP}_{3}$

Figure 4. Insensitivity of the CADPR-induced $\mathrm{Ca}^{2+}$ release to heparin blockage. $\mathrm{Ca}^{2+}$ release from egg homogenates was measured fluorimetrically using fluo 3. A 0.8-ml aliquot of $2.5 \%$ egg homogenate was used in each of the experiments shown. The following additions were made when indicated: CADPR, $0.14 \mu \mathrm{M}$ $\mathrm{IP}_{3}, 0.5 \mu \mathrm{M} ; \mathrm{H}(50), 50 \mu \mathrm{g} / \mathrm{ml}$ heparin; $H(100), 0.1 \mathrm{mg} / \mathrm{ml}$ heparin; $H(187), 0.187 \mathrm{mg} / \mathrm{ml}$ heparin.

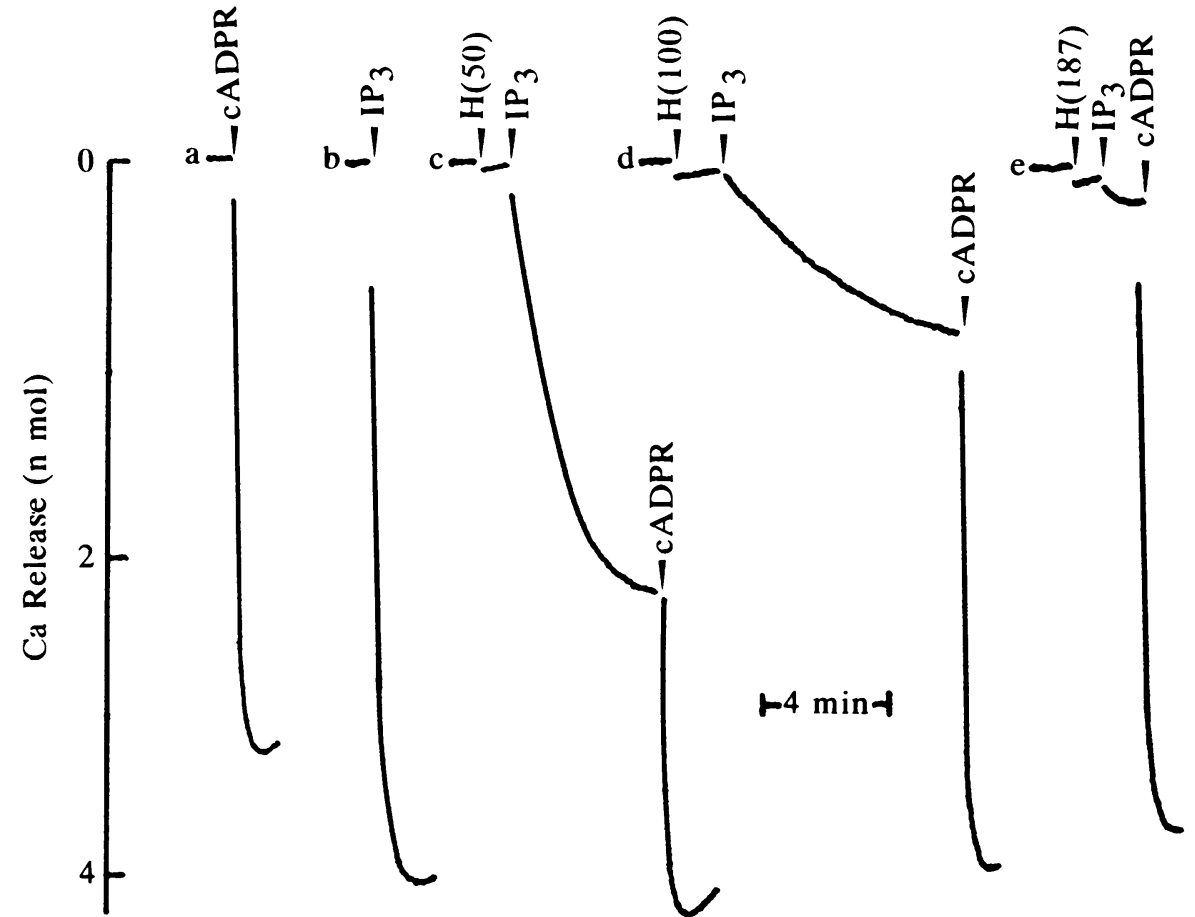

whereas the CADPR-induced release was increased to $\sim 3 \mathrm{nmol}$ (trace d). Finally, when $\mathrm{IP}_{3^{-}}$ induced release was completely blocked by heparin, CADPR was able to release $\sim 4 \mathrm{nmol}$ of $\mathrm{Ca}^{2+}$ (trace e). The total release in all three cases was constant at $\sim 4 \mathrm{nmol}$. It appears that when the $\mathrm{IP}_{3}$-sensitive release was reduced by heparin, more $\mathrm{Ca}^{2+}$ was left for cADPR to release. Partial release of $\mathrm{Ca}^{2+}$ from the microsomes could be induced by the use of submaximal concentration of either activator instead of heparin blockage. Again, if the initial release by one activator was small, the subsequent release by a maximal dose of the other activator was large, and vice versa (data not shown). This inverse relationship between $\mathrm{Ca}^{2+}$ release induced by CADPR and IP ${ }_{3}$ is consistent with both activators releasing $\mathrm{Ca}^{2+}$ from overlapping stores.

If CADPR and IP 3 released $\mathrm{Ca}^{2+}$ from overlapping stores, one would expect their effects to be nonadditive. This was found to be the case, as shown in Figure 5 . In these experiments a $\mathrm{Ca}^{2+}$ electrode was used to monitor $\mathrm{Ca}^{2+}$ release. This was to avoid the possibility of saturating the indicator with potentially large amounts of $\mathrm{Ca}^{2+}$ released by both activators. Figure 5 shows that a maximal dose of $\mathrm{IP}_{3}$ and CADPR each released $\sim 8 \mathrm{nmol}$ of $\mathrm{Ca}^{2+}$. When both were added together, the amount of release was only slightly higher than each alone, indicating nonadditivity. From four similar experiments, the amount of $\mathrm{Ca}^{2+}$ released by cADPR alone was $106 \pm 7.1 \%$ ( \pm SE) of that released by $\mathrm{IP}_{3}$. With both added together, the release was only $137 \pm 6.2 \%$ of $\mathrm{IP}_{3}$ alone, instead of $206 \%$ if they were additive. The last tracing in Figure 5 shows a control experiment where addition of a 21-times-more-concentrated ADP-ribose, a hydrolysis product of cADPR (Lee et al., 1989), did not produce any $\mathrm{Ca}^{2+}$ release.

\section{Mobilization of $\mathrm{Ca}^{2+}$ in intact eggs}

Results presented above establish that CADPR is a potent activator of $\mathrm{Ca}^{2+}$ release from egg microsomes. To show that CADPR can actually mobilize $\mathrm{Ca}^{2+}$ from live eggs, we used microinjection to introduce it into the eggs. The intracellular $\mathrm{Ca}^{2+}$ was measured with a fluorescent indicator, indo 1 , which was microinjected into the egg. A silicon-intensified target television camera was used to monitor the fluorescence from the egg. The fluorescence intensity at $\mathbf{4 0 5}$ $\mathrm{nm}$ and $485 \mathrm{~nm}$ was sampled alternately using a rotating wheel filter changer. The egg was then impaled with a second micropipette containing $10 \mu \mathrm{M}$ of CADPR in the injection buffer. The lower panel of Figure 6 shows the time course of fluorescence intensity changes at the two monitored wavelengths. At the time indi- 


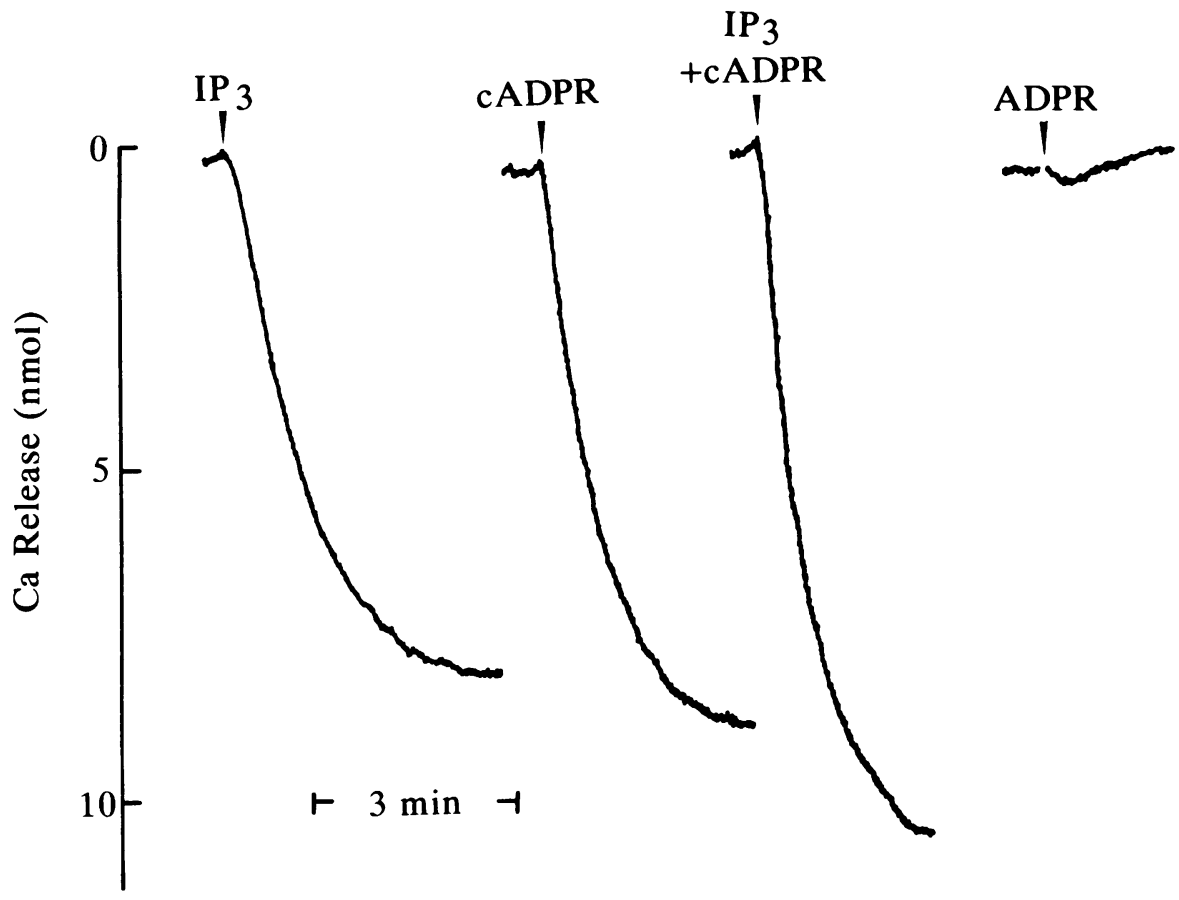

Figure 5. Nonadditivity of $\mathrm{Ca}^{2+}$ release induced by CADPR and $\mathrm{IP}_{3} . \mathrm{Ca}^{2+} \mathrm{re}-$ lease was measured using a $\mathrm{Ca}^{2+}$-specific minielectrode. A $0.5-\mathrm{ml}$ aliquot of egg homogenate $(2.5 \%)$ was used in each of the experiments shown. The following additions were made when indicated: $\mathrm{PP}_{3}, 1 \mu \mathrm{M}$; CADPR, $0.58 \mu \mathrm{M} ; \mathrm{IP}_{3}+$ CADPR, $1 \mu \mathrm{M}$ $\mathrm{IP}_{3}$ and $0.58 \mu \mathrm{M}$ CADPR added together; ADP-ribose (ADPR), $12.5 \mu \mathrm{M}$. cated by the arrow in the top panel, $10 \mathrm{pl}$ of 10 $\mu \mathrm{M}$ cADPR was injected into the egg using a pressure pulse. This resulted in a rapid decrease in fluorescence at $485 \mathrm{~nm}$ and a concomitant increase in fluorescence at $405 \mathrm{~nm}$. After reaching the peak, the fluorescence intensities at both wavelengths gradually returned to their respective basal levels. To correct for autofluorescence, an adjacent egg, not loaded with indo 1 , was also monitored at the two wavelengths and is shown on the lower panel as background. The upper panel in Figure 6 shows the ratio of the intensity at the two wavelengths after the background was subtracted. Injection of cADPR induced a transient increase of the ratio from a basal value of $\sim 0.2$ to a peak of $\sim 0.8$ and was followed by a gradual decline to the original value. Calibration using Ca-EGTA buffers indicated that a ratio of 0.2 and 0.8 corresponded to free- $\mathrm{Ca}^{2+}$ concentrations of $\sim 0.2$ $\mu \mathrm{M}$ and $1 \mu \mathrm{M}$, respectively. Visual inspection of the injected egg afterward showed that the cortical reaction had occurred, providing further evidence that CADPR did release $\mathrm{Ca}^{2+}$ in the egg.

Figure 7 compares the dose-response relationships of $C A D P R$ and $\mathrm{IP}_{3}$ using the cortical reaction as an indicator of intracellular $\mathrm{Ca}^{2+}$ change. Eggs were microinjected with $10 \mathrm{pl}$ of various concentrations of the two activators and scored for full or partial cortical reaction. The reaction was scored as full if the fertilization membrane completely surrounded the egg and partial if only part of the egg was surrounded. As can be seen from the figure, CADPR was as effective as $\mathrm{IP}_{3}$ in inducing the cortical reaction. The half-maximal doses for the two activators were both at $\sim 10 \mathrm{pl}$ of $4 \mu \mathrm{M}$. Because the injection volume was $\sim 1.5 \%$ of the cell volume, the half-maximal concentration in the egg should be $\sim 60 \mathrm{nM}$, assuming uniform distribution. This was in the same range as determined in the homogenate system. At $10 \mathrm{pl}$ of $10 \mu \mathrm{M}$ of either activator, $80-100 \%$ of the injected eggs underwent full or partial cortical reaction. On the other hand, none of the 16 eggs injected with $10 \mathrm{pl}$ of $1 \mu \mathrm{M}$ of either activator had cortical reaction. This served as a good control, showing that the injection buffer and the process of microinjection did not cause any $\mathrm{Ca}^{2+}$ changes in the eggs. Other control injections (10 pl) performed were as follows: $1 \mathrm{mM}$ $\mathrm{NAD}^{+}, 10$ out of 10 showed no reaction; $50 \mu \mathrm{M}$ ADP-ribose, 3 out of 3 showed no reaction; 30 $\mu \mathrm{M}$ heat-inactivated CADPR (30 min in boiling water), 9 out of 9 showed no reaction. Finally, a blind experiment was performed. Coded samples containing either $30 \mu \mathrm{M}$ of CADPR or 30 $\mu \mathrm{M}$ of heated cADPR were used. The result was seven out of seven injected with cADPR gave full cortical reaction, whereas six out of six injected with heated CADPR did not react.

The $\mathrm{Ca}^{2+}$ mobilized by $\mathrm{CADPR}$ and $\mathrm{IP}_{3}$ was from internal stores because both activators 
$\mathrm{Ca}^{2+}$ mobilization by cyclic ADP-ribose and $\mathrm{IP}_{3}$

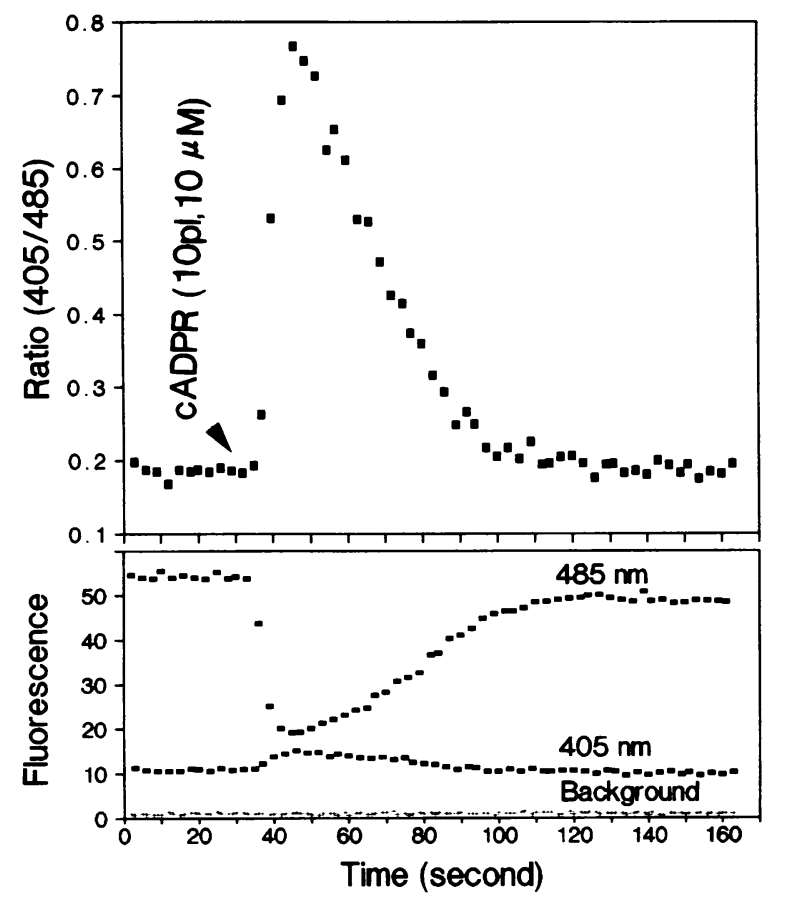

Figure 6. Intracellular $\mathrm{Ca}^{2+}$ changes induced by CADPR. The egg was first injected with the $\mathrm{Ca}^{2+}$ indicator indo 1 and then impaled by another micropipette containing 10 $\mu \mathrm{M}$ CADPR in the injection buffer. The lower panel shows the intensity measurements at $405 \mathrm{~nm}$ and $485 \mathrm{~nm}$ of the loaded egg as well as the background. The upper panel shows the calculated fluorescence ratio. At the time indicated, a $10 \mathrm{pl}$ of $10 \mu \mathrm{M}$ of cADPR was injected into the egg.

were equally effective in inducing a cortical reaction in the presence or absence of external $\mathrm{Ca}^{2+}$. This is shown in Figure 8. Eggs were washed three times in $\mathrm{Ca}^{2+}$-free seawater containing $1 \mathrm{mM}$ EGTA and resuspended in either the same medium or in regular seawater containing $10 \mathrm{mM} \mathrm{Ca}{ }^{2+}$. The eggs were then injected with $10 \mathrm{pl}$ of either $5 \mu \mathrm{M}$ of CADPR or 3 $\mu \mathrm{M}$ of $\mathrm{IP}_{3}$ and scored for cortical reaction. As can be seen from the figure, $90-100 \%$ of the injected eggs showed partial or full cortical reaction whether external $\mathrm{Ca}^{2+}$ was present or not. The batch of eggs used in this experiment appeared to be slightly more sensitive to $\mathrm{IP}_{3}$ than CADPR, as more partials were scored with CADPR.

\section{Parthenogenetic egg activation induced by CADPR and $I P_{3}$}

Time lapse video-microscopy was used to observe subsequent development of eggs injected with either CADPR or $I_{3}$. Figure $9, A-E$, is a series of photographs taken directly from the video screen at various times after injection.

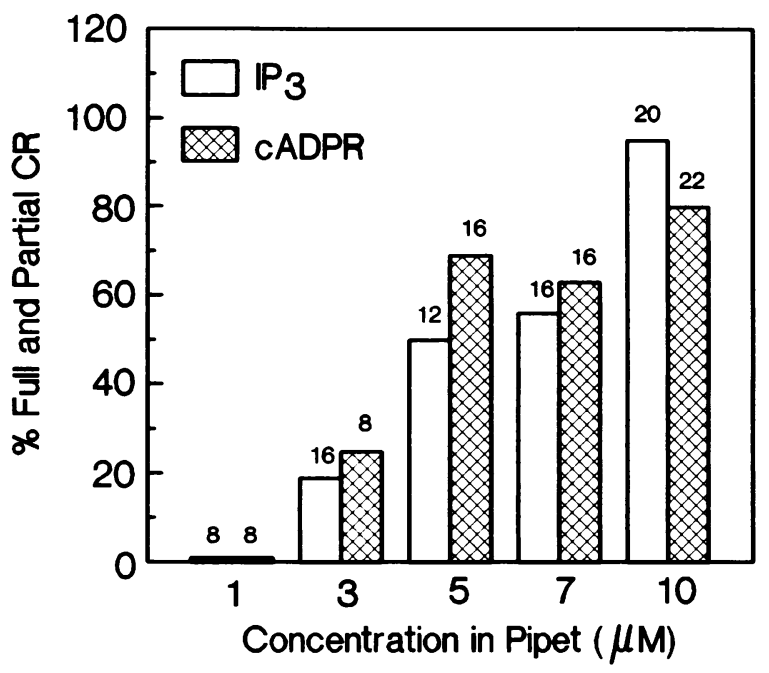

Figure 7. Comparison of dose-response of CADPR and $I_{\mathbf{3}}$ microinjected into eggs. Eggs were microinjected with $10 \mathrm{pl}$ of the indicated concentration of CADPR or $\mathrm{IP}_{3}$ and scored for cortical reaction. The number on top of each bar indicates the total number of eggs injected with that particular concentration.

Three eggs are shown. One was injected with $10 \mathrm{pl}$ of $20 \mu \mathrm{M}$ CADPR (labeled c), one was injected with $10 \mathrm{pl}$ of $20 \mu \mathrm{M} I \mathrm{P}_{3}$ (labeled i), and one was fertilized (labeled f). At $29 \mathrm{~min}$ after injection (Figure 9A), nuclei in all three eggs were clearly visible (indicated by arrows). The nuclei in the fertilized egg and the one injected with cADPR disappeared at 59 min after injection (Figure 9B), indicating that nuclear membrane breakdown had occurred. The one injected with $\mathrm{IP}_{3}$ underwent cortical contraction

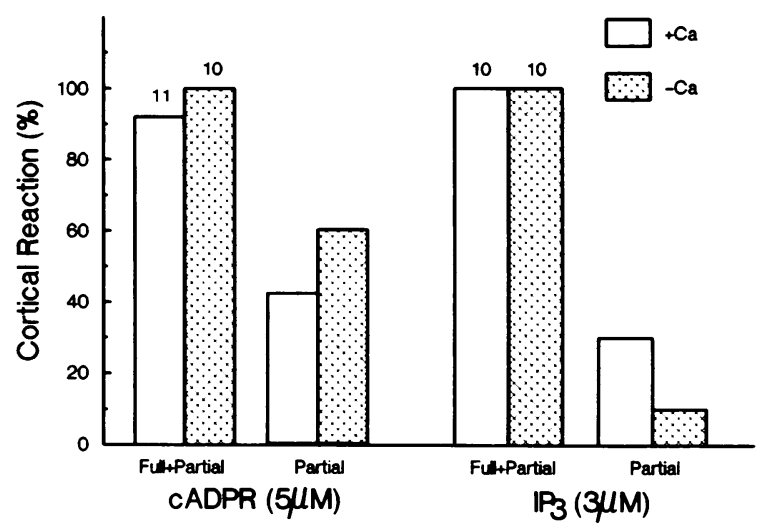

Figure 8. Independence of the effects of CADPR and $I P_{3}$ on external $\mathrm{Ca}^{2+}$. Eggs were incubated in the presence or absence of external $\mathrm{Ca}^{2+}$ and microinjected with $10 \mathrm{pl}$ of either $5 \mu \mathrm{M}$ of CADPR or $3 \mu \mathrm{M}$ of $\mathrm{IP}_{3}$. Full and partial cortical reactions were scored. The number on top of each bar indicates the total of eggs injected under that condition. 

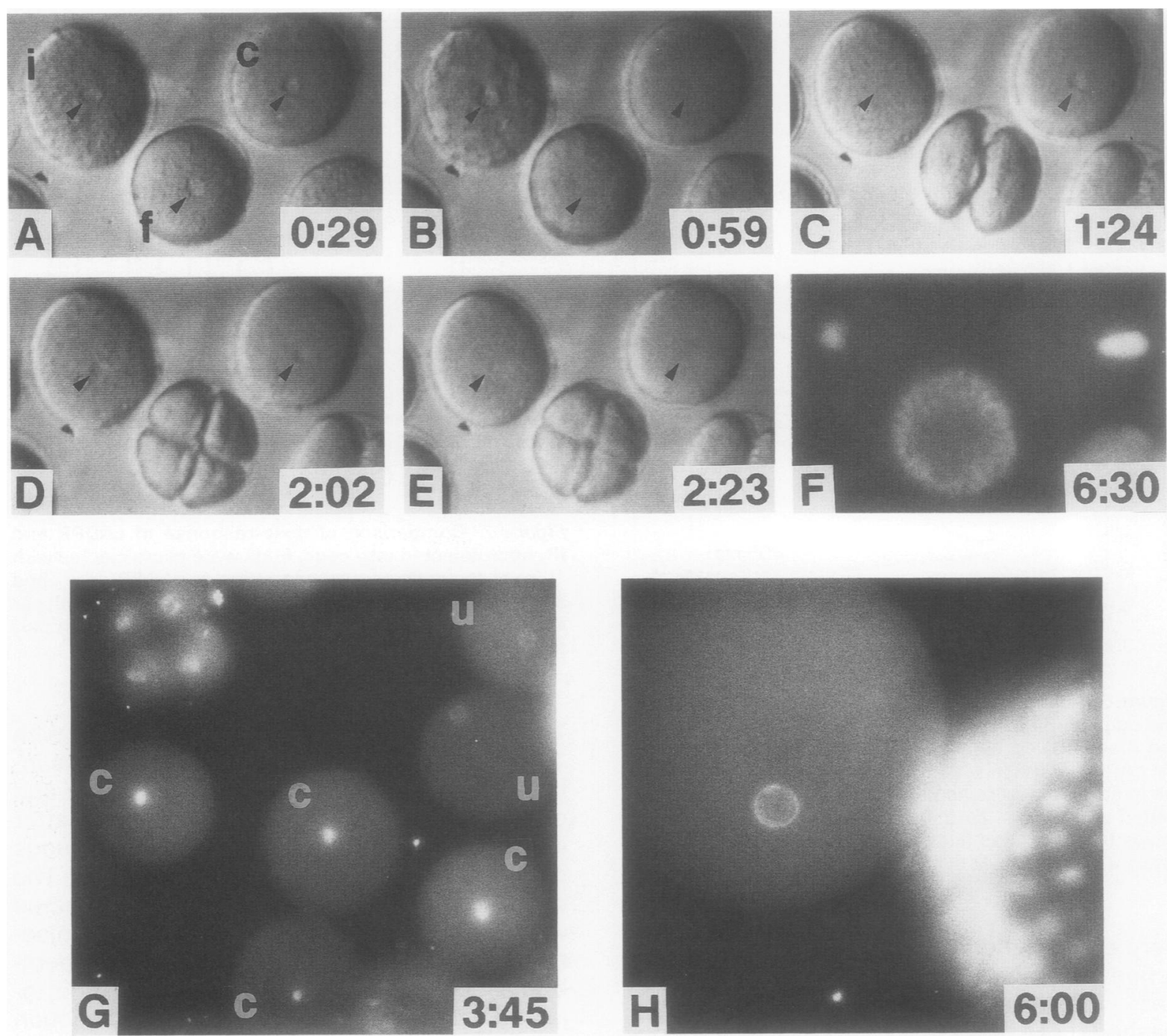

Figure 9. Parthenogenetic activation induced by $c A D P R$ and $I P_{3}$. A-E. Time-lapse video-micrographs of eggs injected either with $10 \mathrm{pl}$ of $20 \mu \mathrm{M}$ cADPR (labeled c) or with the same dose of $\mathrm{IP}_{3}$ (labeled i). Also shown in the same field is a fertilized egg (labeled f). Arrows indicate positions of the nuclei. Times after injection are shown in the lower righthand corners as hour:minute. F. A fluorescence micrograph of the eggs at 6-1/2 $\mathrm{h}$ after injection. The eggs were stained with a DNA dye, Hoechst $33342(0.1 \mathrm{mM}$ in seawater), to reveal the chromosomal materials. G. Another fluorescence micrograph of eggs injected with $10 \mathrm{pl}$ of $20 \mu \mathrm{M}$ cADPR (labeled c). For comparison, two unfertilized eggs (labeled $\mathrm{u}$ ) and an embryo at the fourcell stage can be seen in the same field. The nuclei of the unfertilized eggs had a characteristic ringlike appearance. Some sperm nuclei can be seen scattered in field. $H$. A fluorescence micrograph of an egg injected with $10 \mathrm{pl}$ of $50 \mu \mathrm{M} \mathrm{ADP}$-ribose as control (left). The egg was stained $6 \mathrm{~h}$ after the injection, and the nucleus showed ringlike staining similar to unfertilized eggs. A multicell embryo is seen to its right. The magnification of this micrograph is two times that of A-G.

and the cell appeared wrinkled. The nucleus was still visible. Nuclear membrane breakdown occurred in this egg $30 \mathrm{~min}$ later (Figure 9C), and the cell smoothed out. During the same period the fertilized egg had divided and the nucleus in the cADPR-injected egg reappeared. Although none of the injected eggs divided, they did undergo a cycle of nuclear membrane breakdown and reformation.

Two hours after injection, the nucleus in the $\mathrm{IP}_{3}$-injected egg reappeared, and the fertilized egg had gone through a second division (Figure 9D). Thirty min later the nuclei of both injected eggs disappeared again (Figure 9E). The nuclear cycling continued on in the injected eggs for many hours. At $6-1 / 2 \mathrm{~h}$ after injection, the cells were stained with a fluorescent DNA dye (Hoechst 33342) to visualize the chromosomes. As shown in Figure $9 F$, both injected eggs showed large quantities of highly fluorescent chromosomal material. 
$\mathrm{Ca}^{2+}$ mobilization by cyclic ADP-ribose and $\mathrm{IP}_{3}$

Figure 9G shows the result of another experiment comparing the DNA-staining pattern of cADPR-injected eggs with unfertilized eggs and embryos. The pronuclei of unfertilized eggs (labeled $u$ ) showed only faint, ringlike staining. In contrast, nuclei of eggs injected with CADPR were larger and showed intense solid staining similar to the four-cell embryo. The nuclear staining of the injected eggs was not as extensive as shown in Figure 9F because the staining was done at $3 \mathrm{~h} 45 \mathrm{~min}$ after the injection instead. A few sperm nuclei can be seen scattered in the field. Figure $9 \mathrm{H}$ shows an embryo adjacent to a control egg injected with $10 \mathrm{pl}$ of $50 \mu \mathrm{M}$ of ADP-ribose. The staining was done $6 \mathrm{~h}$ after the injection, and the egg still showed the ringlike staining characteristic of an unfertilized egg. The magnification of this micrograph was higher than Figure 9, A-G.

In a series of experiments, a total of 15 eggs were injected with CADPR, and 13 of them went through multiple nuclear cycles. All of them also had large amount of chromosomal materials intensely stained by the DNA dye. One of the 15 injected eggs lysed, and only one was not activated, even though it had cortical reaction and went through the first nuclear membrane breakdown. Of the three eggs that were injected with $\mathrm{IP}_{3}$, all underwent parthenogenetic activation. On the other hand, none of the six control eggs injected with ADP-ribose was activated. It is therefore clear that CADPR not only can mobilize intracellular $\mathrm{Ca}^{2+}$ and induce cortical reaction, it can also parthenogenetically activate the egg to undergo multiple cycles of DNA synthesis.

\section{Discussion}

Two different methods were used in this study to measure $\mathrm{Ca}^{2+}$ mobilization in the egg homogenate system. The first one was a fluorimetric method using $\mathrm{Ca}^{2+}$ indicators. Most of the experiments presented here used the newly available indicator fluo 3, although we have previously used other indicators such as quin 2, fura 2, and indo 1 (Clapper and Lee, 1985; Clapper et al., 1987, Lee et al., 1989; Rusinko and Lee, 1989). The fact that four structurally different indicators all report similar results argues against the possibility that the CADPR-induced response was due to some artifactual interactions with the $\mathrm{Ca}^{2+}$ indicators. The second method we used was a $\mathrm{Ca}^{2+}$-specific minielectrode. This method was technically more demanding, but it provided us with a completely independent way for verifying the results obtained with indicators.
Using these two methods, we showed that the CADPR-induced response was due to $\mathrm{Ca}^{2+}$ because it could be eliminated by increasing specifically the $\mathrm{Ca}^{2+}$-buffering power of the homogenate. That the $\mathrm{Ca}^{2+}$ did not come from contamination in the CADPR sample was shown by the fact that heating could destroy its activity. The $\mathrm{Ca}^{2+}$, therefore, had to be released from the microsomes. cADPR could release $\mathrm{Ca}^{2+}$ from the microsomes by inhibiting the $\mathrm{Ca}^{2+}$ transport mechanism. This was not likely because blocking the transport by removal of ATP induced only slow leakage of $\mathrm{Ca}^{2+}$ instead of the rapid release seen with cADPR. The possibility that CADPR was acting like a $\mathrm{Ca}^{2+}$ ionophore was also ruled out because a large dose of cADPR did not simply release all microsomal $\mathrm{Ca}^{2+}$, as would be expected of a general ionophore, but induced specific desensitization to itself instead. Other unrelated activators, such as $\mathrm{IP}_{3}$ or ionomycin, could still release $\mathrm{Ca}^{2+}$ from the microsomes. This indicated that the release requires specific functioning of the microsomes and suggested that CADPR may be operating through a receptor system. This is supported by the very low half-maximal effective concentration of CADPR. Indeed, the measured value of $18 \mathrm{nM}$ was 7 times less than that of $I \mathrm{P}_{3}$ measured in the same egg homogenate preparation.

The possibility that CADPR is acting on the same receptor as $\mathrm{IP}_{3}$ was investigated by blocking the $\mathrm{IP}_{3}$-induced $\mathrm{Ca}^{2+}$ release with heparin, a competitive inhibitor of $\mathrm{IP}_{3}$ binding to its receptor (Worley et al., 1987). It was found that cADPR was fully active even when the $\mathrm{IP}_{3}$ effect was completely blocked. This indicated that either CADPR was acting on a completely separate receptor system or that CADPR actually has a much higher affinity for the $\mathrm{IP}_{3}$ receptor than heparin or $\mathrm{IP}_{3}$ itself. The latter possibility can be ruled out because a large dose of CADPR did not block the $\mathrm{IP}_{3}$ effect but instead desensitized the microsomes to itself only. Therefore, it can be concluded that there are at least two separate systems for mobilizing internal $\mathrm{Ca}^{2+}$ in sea urchin eggs.

The question of whether these two systems release $\mathrm{Ca}^{2+}$ from different storage compartments was investigated next. Three lines of evidence suggest that the two activators release $\mathrm{Ca}^{2+}$ from substantially overlapping stores. First, the amounts of $\mathrm{Ca}^{2+}$ released by the two were not additive. In fact, adding both together to the egg homogenate gave only $20-30 \%$ more $\mathrm{Ca}^{2+}$ release than each individually. Second, the amounts of $\mathrm{Ca}^{2+}$ released by the two activators are inversely related. If the $\mathrm{Ca}^{2+}$ released by one 
activator was small either because of the use of a submaximal dose or heparin blockage, subsequent release by a maximal dose of the other activator would be large, and vice versa. The total amount of releasable $\mathrm{Ca}^{2+}$ remained relatively constant. Third, we have previously shown that both CADPR- and $\mathrm{IP}_{3}$-sensitive microsomes co-purified in a Percoll gradient and were well separated from the mitochondria (Clapper et al., 1987). All this evidence indicates that there is substantial overlap of the $\mathrm{Ca}^{2+}$ stores for the two activators.

Measurements of the marker enzyme distribution showed the CADPR- and $\mathrm{IP}_{3}$-sensitive $\mathrm{Ca}^{2+}$ stores co-purified with glucose 6-phosphatase, suggesting they may be part of the endoplasmic reticulum network (Clapper and Lee, 1985; Clapper et al., 1987). It is conceivable that this extensive internal membrane network could contain more than one receptor for $\mathrm{Ca}^{2+}$ mobilization. Indeed, one can envision that various receptors could be distributed nonuniformly along the network, with specific receptors concentrated on special regions. This could account for our observation that a small portion of the $\mathrm{Ca}^{2+}$ release was apparently from nonoverlapping stores. Indeed, we found that when CADPR and $\mathrm{IP}_{3}$ were added together, there was 20-30\% more $\mathrm{Ca}^{2+}$ released than for each alone. This small portion of nonoverlapping stores could be due to a pinching off of some of these special regions during homogenization, forming noncommunicating vesicles containing mainly one type of receptor. An attractive advantage of regional concentration of receptors is that it would allow spatially localized release of $\mathrm{Ca}^{2+}$ from the network. Indeed, striking spatial inhomogeneity of $\mathrm{Ca}^{2+}$ mobilization has been observed in sea urchin eggs (Eisen et al., 1984) as well as in various other cell types (Connor, 1986; Sawyer et al., 1985).

To demonstrate that CADPR is active in live cells, we used microinjection to introduce it into intact eggs. Control injections were done with heat-inactivated CADPR, NAD ${ }^{+}$(the precursor of CADPR), or ADP-ribose (the hydrolysis product of CADPR). None of these produced any cortical reaction. Indeed, a blind experiment, using coded samples of heat-inactivated CADPR and CADPR, showed conclusively that only cADPR was active. Comparison of the dose-response with that of $\mathrm{IP}_{3}$ indicated that it was as effective as $I P_{3}$ in inducing the cortical reaction. The sources of $\mathrm{Ca}^{2+}$ for the two activators were internal because both were active in the absence of external $\mathrm{Ca}^{2+}$. In addition to inducing intracellular $\mathrm{Ca}^{2+}$ changes and the cortical re- action, both cADPR and $I P_{3}$ were also effective in activating the eggs to undergo multiple cycles of nuclear membrane breakdown and DNA synthesis. It is clear, therefore, that CADPR is active not only in the egg homogenate but can actually mobilize $\mathrm{Ca}^{2+}$ in live eggs as well as induce parthenogenetic activation.

Results presented in this study clearly establish the existence of a $\mathrm{Ca}^{2+}$-release mechanism in the eggs that is completely separated from the $I P_{3}$-dependent system. The fact that this release mechanism can be triggered effectively by a natural metabolite of $\mathrm{NAD}^{+}$strongly suggests that it has physiological relevance. This is further strengthened by our previous finding that the enzyme responsible for synthesizing CADPR is present not only in sea urchin, an invertebrate, but also in all mammalian tissues we have investigated, including human platelets (Rusinko and Lee, 1989). The conservation of the enzyme activity throughout evolution strongly suggests that the metabolite should have an important biological function. That this function is likely to be mobilization of $\mathrm{Ca}^{2+}$ is indicated by the fact that CADPR was at least as active as $\mathrm{IP}_{3}$, the only known second messenger for $\mathrm{Ca}^{2+}$. Judging from the importance of $\mathrm{Ca}^{2+}$ in regulating various cellular functions, it is perhaps not surprising that there would be more than one second-messenger system for mobilizing the internal stores. Evidence we have accumulated so far suggests that CADPR could be one such messenger.

\section{Methods}

\section{Egg homogenate preparation}

Homogenates were prepared from Lytechinus pictus eggs as described previously (Clapper et al., 1987). Briefly, the eggs were washed once in artificial seawater, twice in $\mathrm{Ca}^{2+}$. free seawater containing $1 \mathrm{mM}$ EGTA, twice in $\mathrm{Ca}^{2+}$-free seawater without EGTA, once with the homogenization buffer (250 mM N-methylglucamine, $250 \mathrm{mM}$ potassium gluconate, $20 \mathrm{mM}$ 4-(2-hydroxyethyl)-1-piperazineethanesulfonic acid, and $1 \mathrm{mM} \mathrm{MgCl} 2 ; \mathrm{pH}$ titrated to 7.2 with acetic acid) and resuspended with the same medium to $10 \%$ (v/ v). The following additions were made: $25 \mu \mathrm{g} / \mathrm{ml}$ of leupeptin, $20 \mu \mathrm{g} / \mathrm{ml}$ of aprotinin, $100 \mu \mathrm{g} / \mathrm{ml}$ of soybean trypsin inhibitor, 4 units $/ \mathrm{ml}$ of creatine kinase, $1 \mathrm{mM}$ ATP, and $8 \mathrm{mM}$ phosphocreatine. Homogenization was performed in a Dounce homogenizer with an " $A$ " pestle. The homogenates were centrifuged for $10 \mathrm{~s}\left(13000 \times \mathrm{g}, 4^{\circ} \mathrm{C}\right)$ in a microfuge (model 235A, Fisher). The supernatant was collected and stored frozen at $-70^{\circ} \mathrm{C}$ until use.

\section{$\mathrm{Ca}^{2+}$-release assays}

Homogenate $(10 \%)$ was thawed in a $17^{\circ} \mathrm{C}$ water bath and then diluted in half with the homogenization medium. After incubating at $17^{\circ} \mathrm{C}$ for $2 \mathrm{~h}$, the homogenate was diluted again in half to $2.5 \%$ with the homogenization medium con- 
taining half the concentrations of ATP, creatine kinase, and phosphocreatine as described above. The $\mathrm{Ca}^{2+}$ indicator (either indo 1 or fluo 3 ) was added to a final concentration of 2-3 $\mu \mathrm{M}$. After another $1 \mathrm{~h}$ of incubation at $17^{\circ} \mathrm{C}$, the homogenates were ready for use.

Fluorescence was measured at 490-nm excitation (5-nm slit) and 535-nm emission (5-nm slit) for fluo 3; 360-nm excitation (5-nm slit) and 485-nm emission (10-nm slit) for indo 1 . The cuvette was maintained at $17^{\circ} \mathrm{C}$ with a circulating water bath and its content continuously mixed with a magnetic stirring bar. The volume of homogenate used was 0.8 $\mathrm{ml}$ unless indicated otherwise. $\mathrm{Ca}^{2+}$ released from the homogenate was calibrated with the addition of a known amount of $\mathrm{Ca}^{2+}$.

$\mathrm{Ca}^{2+}$-specific minielectrodes were made and used as described previously (Clapper and Lee, 1985). Briefly, pieces of tubing with an inner diameter of $2 \mathrm{~mm}$ were dipped into a mixture containing $10 \mu \mathrm{l}$ of $\mathrm{Ca}^{2+}$ electrode cocktail (Fluka) and $60 \mu \mathrm{l}$ of $12 \%(\mathrm{w} / \mathrm{v})$ polyvinyl chloride dissolved in tetrahydrofuran. After drying, electrodes were filled with a buffer containing $90 \mathrm{mM} \mathrm{KCl}, 10 \mathrm{mM}$ EGTA, $5 \mathrm{mM} \mathrm{CaCl}$, $10 \mathrm{mM}$ 4-(2-hydroxyethyl)-1-piperazineethanesulfonic acid, $\mathrm{pH}$ 7.29. The reference electrode (MERE1, World Precision Instruments) was filled with $3 \mathrm{M} \mathrm{KCl}$. The homogenates $(0.5$ $\mathrm{ml}$ ) were maintained at $17^{\circ} \mathrm{C}$ during measurement.

\section{Procedures for microinjection}

Procedures for microinjection were as described previously (Rusinko and Lee, 1989). Briefly, a pressure pulse from a Pneumatic Pico-Pump (WPI) were used to delivered $10 \mathrm{pl}$ of fluid into the impaled egg. The ejection volume was calibrated before and after the injection by measuring the diameter of the droplet ejected into a drop of silicon oil. The initial clearing of organelles during the injection monitored by video-microscopy was also used to estimate the injection volume. The injection volume was $\sim 1.5 \%$ of the egg volume, which was measured to be $\sim 684$ pl. The injection buffer contained $0.5 \mathrm{M} \mathrm{KCl}, 0.1 \mathrm{mM}$ EGTA, $10 \mathrm{mM}$ 4-(2-hydroxyethyl)-1-piperazineethanesulfonic acid, $\mathrm{pH} 6.7$, and various concentrations of CADPR or IP $\mathrm{PP}_{3}$. The temperature was maintained at between 17 and $20^{\circ} \mathrm{C}$ with a circulating bath.

\section{Intracellular $\mathrm{Ca}^{2+}$ measurements}

Intracellular $\mathrm{Ca}^{2+}$ changes were monitored with the $\mathrm{Ca}^{2+}$ indicator indo 1 . Ten picoliters of $10 \mathrm{mM}$ indo 1 in the injection buffer was microinjected into the eggs, giving a final concentration of $\sim 150 \mu \mathrm{M}$ of indo 1. The eggs were excited at $360 \mathrm{~nm}$, and the emission fluorescence was alternately selected at $405 \mathrm{~nm}$ and $485 \mathrm{~nm}$ with the use of a rotating wheel filter changer. The loaded egg was viewed with a $20 \times$ objective and was impaled by another micropipette containing various substances to be injected. Temperature was maintained at between 17 and $20^{\circ} \mathrm{C}$ with a circulating water bath. Fluorescence was monitored with a silicon-intensified target camera (RCA TC1030/H), and the images were captured with a frame grabber (PCVISIONplus, Imaging Technology). Normally, quantitative measurements were done on two areas in the field and each was of $10 \times 10$ pixels. One measuring area was put on the injected egg and the other on an adjacent egg which was not injected. Measurements from the latter were used for background correction. Fluorescence intensities of all the pixels in the measured areas were averaged. After subtracting the background readings, the ratio of the average intensity at the two wavelengths was calculated. To calibrate the response of indo 1 , fluorescence ratios were measured using the same system on droplets of Ca-EGTA buffers containing $120 \mu \mathrm{M}$ of the indicator. These buffer droplets of the size of an egg were formed by ejecting the buffers into a drop of silicon oil. A ratio of 0.2 and 0.8 corresponded to a free- $\mathrm{Ca}^{2+}$ concentration of $\sim 0.2 \mu \mathrm{M}$ and $1 \mu \mathrm{M}$, respectively.

\section{Materials}

Sea urchins (Lytechinus pictus) were obtained from Marinus, Inc., Long Beach, CA. The metabolite, cADPR, was prepared by incubating $\mathrm{NAD}^{+}$with sea urchin egg extracts and purified by high-performance liquid chromatography procedures as described previously (Lee et al., 1989). Concentrations were determined by absorbance at $254 \mathrm{~nm}$ and an extinction coefficient of 14300 (Lee et al., 1989). The concentration of contaminating $\mathrm{Ca}^{2+}$ in the CADPR sample was measured by the fluo 3 method to be $\sim 1.4 \%$ of the cADPR concentration. $\mathrm{IP}_{3}$ was purchased from Calbiochem and stock solutions were made by weighing out 1-2 $\mathrm{mg}$ of material. The concentration was then verified with an organic phosphate assay (Hess and Derr, 1975). Indo 1 and fluo 3 were from Molecular Probes. Apyrase and heparin (MW 4000-6000, H5765) were from Sigma.

\section{Acknowledgments}

We thank Robert Aarhus for technical assistance and Dr. David Levitt for critical reading of the manuscript. This work was supported by National Institutes of Health Grant HD17484 (to H.C.L.)

Received: December 14, 1989.

Revised and accepted: January 16, 1990.

\section{References}

Berridge, M.J., and Irvine, R.F. (1989). Inositol phosphates and cell signaling. Nature 341, 197-205.

Changya, L., Gallacher, D.V., Irvine, R.F., Potter, B.V.L. and Petersen, O.H. (1989). Inositol 1,3,4,5-tetrakisphosphate is essential for sustained activation of the $\mathrm{Ca}^{2+}$-dependent $\mathrm{K}^{+}$ current in single internally perfused lacrimal acinar cells. J. Membr. Biol. 109, 85-93.

Clapper, D.L. and Lee, H.C. (1985). Inositol trisphosphate induces calcium release from nonmitochondrial stores in sea urchin egg homogenates. J. Biol. Chem. 260, 1394713954.

Clapper, D.L., Walseth, T.F., Dargie, P.J. and Lee, H.C. (1987). Pyridine nucleotide metabolites stimulate calcium release from sea urchin egg microsomes desensitized to inositol trisphosphate. J. Biol. Chem. 262, 9561-9568.

Connor, J.A. (1986). Digital imaging of free calcium changes and of spatial gradients in growing processes in single, mammalian central nervous system cells. Proc. Natl. Acad. Sci. USA 83, 6179-6183.

Eisen, A., Kiehardt, D.P., Wieland, S.J. and Reynolds, G.T. (1984). Temporal sequences and spatial distribution of early events of fertilization in single sea urchin eggs. J. Cell Biol. 99, 1647-1654.

Hess, H.H. and Derr, J.E. (1975). Assay of inorganic and organic phosphorus in the 0.1-5 nanomole range. Anal. Biochem. 63, 607-613.

Kamel, L.C., Bailey, J., Schoenbaum, L. and Kinsey, W. (1985). Phosphatidylinositol metabolism during fertilization in the sea urchin egg. Lipids 20, 350-356. 


\section{P.J. Dargie et al.}

Lee, H.C., Walseth, T.F., Bratt, G.T., Hayes, R.N. and Clapper, D.L. (1989). Structural determination of a cyclic metabolite of $\mathrm{NAD}^{+}$with intracellular $\mathrm{Ca}^{2+}$-mobilizing activity. J. Biol. Chem. 264, 1608-1615.

Nishizuka, Y. (1984). The role of protein kinase C in cell surface signal transduction and tumor promotion. Nature 308, 693-698.

Poenie, M., Alderton, J., Tsien, R.Y. and Steinhardt, R.A. (1985). Changes in free calcium with stages of the cell division cycle. Nature 315, 147-149.

Rusinko, N. and Lee, H.C. (1989). Widespread occurrence in animal tissues of an enzyme catalyzing the conversion of $\mathrm{NAD}^{+}$into a cyclic metabolite with intracellular $\mathrm{Ca}^{2+}-\mathrm{mo}-$ bilizing activity. J. Biol. Chem. 264, 11725-11731.

Sawyer, D.W., Sullivan, J.A. and Mandell, G.L. (1985). Intracellular free calcium localization in neutrophils during phagocytosis. Science 230, 663-665.
Schmidt, T., Patton, C. and Epel, D. (1982). Is there a role for the $\mathrm{Ca}^{2+}$ influx during fertilization of the sea urchin egg? Dev. Biol. 90, 284-290.

Supattapone, S., Worley, P.F., Baraban, J.M., and Snyder, S.H. (1988). Solubilization, purification, and characterization of an inositol trisphosphate receptor. J. Biol. Chem. 263, 1530-1534.

Swann, K. and Whitaker, M. (1986). The part played by inositol trisphosphate and calcium in the propagation of the fertilization wave in sea urchin eggs. J. Cell Biol. 103, 23332342.

Wilson, D.B., Connolly, T.M., Bross, T.E., Majerus, P.N., Sherman, W.R., Tyler, A.W., Rubin, L.J. and Brown, J.E. (1985). Isolation and characterization of the inositol cyclic phosphate products of polyphosphoinositide cleavage by phospholipase C. J. Biol. Chem. 260, 13496-13501.

Worley, P.F., Baraban, J.M., Colvin, J.S. and Snyder, S.H. (1987). Characterization of inositol trisphosphate receptor binding in brain. Regulation by $\mathrm{pH}$ and calcium. J. Biol. Chem. 262, 12132-12136. 